\title{
Mucoid degeneration of the posterior cruciate ligament in a college soccer player: a case report
}

Ryo Kanto ${ }^{1 *}\left(\mathbb{0}\right.$, Hiroshi Nakayama ${ }^{1}$, Tomoya Iseki ${ }^{1}$, Shintaro Onishi ${ }^{1}$, Ryo Iwakura', Shinichi Yoshiya ${ }^{2}$ and Toshiya Tachibana'

\begin{abstract}
Background: To the best of our knowledge, arthroscopic treatment for symptomatic mucoid degeneration of the posterior cruciate ligament in young athletes has not been reported before.

Case presentation: An 18-year-old Asian male college soccer player presented with a 3-month history of right knee pain without episodes of trauma. Despite conservative treatment over the preceding 3 months, his symptoms persisted. Physical examination of the right knee revealed full range of motion, though posterior knee pain was induced when the knee approached full flexion. On ligament examination, posterior sagging and Lachman test were negative, and no clinical finding indicative of ligament insufficiency was noted. Magnetic resonance imaging showed a diffusely thickened posterior cruciate ligament with increased signal intensity on the T2-weighted sequence. A few intact fibers were observed with continuous margin from origin to insertion. Based on the patient's history and the magnetic resonance imaging findings, we suspected mucoid degeneration of the posterior cruciate ligament as the cause of the patient's symptoms. Since conservative treatment had failed to relieve the symptoms, arthroscopic treatment was indicated. Arthroscopic examination revealed yellowish crumbly tissues along the thickened posterior cruciate ligament. Tension and bulk of the posterior cruciate ligament were well preserved. Curettage of degenerative tissue and decompression of the posterior cruciate ligament resulted in symptom relief without instability of the knee joint. The patient returned to play at 3 months. At 12 months, postoperative magnetic resonance imaging showed no evidence of recurrence and indicated that the remaining posterior cruciate ligament was thicker than before the surgery. At 2 years follow-up, the patient remained asymptomatic and could play soccer at the same level as before the onset of pain.
\end{abstract}

Conclusions: Arthroscopic decompression of the posterior cruciate ligament may relieve knee pain and facilitate early return to play with good functional results.

Keywords: Mucoid degeneration, PCL, Young athlete

*Correspondence: ryokanto710@gmail.com

${ }^{1}$ Department of Orthopaedic Surgery, Hyogo College of Medicine, 1-1 Mukogawa-cho, Nishinomiya, Hyogo 663-8501, Japan

Full list of author information is available at the end of the article

\section{Background}

Although mucoid degeneration of anterior cruciate ligament (ACL) has been sporadically reported [1], the same pathology in the posterior cruciate ligament (PCL) is less common, with only a small number of cases reported in English literature [2-6]. To our knowledge, arthroscopic treatment for symptomatic mucoid degeneration of the PCL in athletes has not been reported before. We report original author(s) and the source, provide a link to the Creative Commons licence, and indicate if changes were made. The images or other third party material in this article are included in the article's Creative Commons licence, unless indicated otherwise in a credit line to the material. If material is not included in the article's Creative Commons licence and your intended use is not permitted by statutory regulation or exceeds the permitted use, you will need to obtain permission directly from the copyright holder. To view a copy of this licence, visit http://creativecommons.org/licenses/by/4.0/. The Creative Commons Public Domain Dedication waiver (http://creativeco mmons.org/publicdomain/zero/1.0/) applies to the data made available in this article, unless otherwise stated in a credit line to the data. 
herein a case of mucoid degeneration of the PCL with complaints of posterior knee pain during sports activity, which was successfully managed with arthroscopic debridement.

\section{Case presentation}

An 18-year-old Asian male college soccer player presented with a 3-month history of right knee pain. Prior to the onset of symptoms, no episodes of trauma or previous knee problems were noted. Despite conservative treatment over the preceding 3 months consisting of stretching, isometric quadriceps/hamstring strengthening exercises, and medication, his symptoms persisted, and he had not been able to participate in practice sessions or games. The pain aggravated with increased activity. Physical examination of the right knee revealed full range of motion, though posterior knee pain was induced when the knee approached full flexion. On ligament examination, posterior sagging and Lachman test were negative, and no clinical finding indicative of ligament insufficiency was noted. Radiograph of the knee was normal. Magnetic resonance imaging (MRI) revealed longitudinal increased signal intensity area within the PCL on T2-weighed images with an adjacent defined rim of hypointense PCL fibers (Fig. 1). The characteristics of those images were coincident with a "Tram-Track" appearance according to the description by McMonagle et al. [7]. Based on the patient's history and the MRI findings, we suspected mucoid degeneration of the PCL as the cause of the patient's symptoms. Since conservative treatment had failed to relieve the symptoms, arthroscopic treatment was indicated.

Arthroscopic examination revealed yellowish crumbly tissues along the thickened PCL. Tension and bulk of the PCL were well preserved. Other intraarticular tissues such as ACL, menisci, and cartilage were intact. The PCL tissue was split, and evidently degenerated tissue was carefully removed while meticulous care was taken to preserve the longitudinal fiber of the PCL. On arthroscopic observation, the yellowish tissue was present in deeper regions while retention of fluid was not observed within the ligament substance. Histological examination of the specimen obtained from the yellowish degenerative lesion of PCL revealed loose fibrocollagenous tissue containing myxedematous changes indicative of mucoid degeneration of the ligament (Fig. 2).

Postoperatively, the patient was allowed to bear full weight on the following day. Rehabilitation protocol including early motion and quadriceps strengthening exercise was started from the first postoperative week. Running and agility training was started at 6 weeks. The patient returned to play at 3 months. At 12 months, postoperative MRIs showed no evidence of recurrence and indicated that the remaining PCL was thicker than before the surgery (Fig. 3). At 2 years follow-up, the patient remained asymptomatic and could play soccer at the same level as before the onset of pain. The preoperative International Knee Documentation Committee knee subjective score of 40.2 points improved to 98.6 points at 2 years after surgery. The patients and their families were informed that data from the case would be submitted for publication, and gave their consent.

\section{Discussion}

Although rare, mucoid degeneration of the PCL can be a source of activity-related pain in athletes. As a point of reference, Bergin et al. [1] reported that the incidence of mucoid degeneration in ACL is $1.0 \%$ (44/4221), and McMonagle et al. [7] reported that the incidence of PCL mucoid degeneration is $0.1 \%$ $(14 / 12,972)$. To our knowledge, only five cases of symptomatic mucoid degeneration of the PCL have been previously reported. A review of these five cases indicated that mucoid degeneration of the PCL generally affects middle-aged patients with ages ranging from 36 to 65 years, in contrast to the present patient, who was 18 [2-6]. Mucoid degeneration of the cruciate ligaments is usually asymptomatic, and is often hard to diagnose clinically owing to the lack of specific symptoms and signs. However, MRI findings in sagittal plane show longitudinal layers of increased signal intensity on T2-weighted images within the ligament substance with an adjacent well-defined intact rim of hypointense PCL fibers that give the PCL a "tram-track" appearance [7]. Its clinical symptoms were characterized by posterior knee pain on deep knee flexion without causative or preceding injuries. To date, the mechanism underlying knee pain in mucoid degeneration of the PCL is controversial. According to previous studies, increased volume of the PCL and resultant increases in internal pressure within the notch have been considered a cause of knee pain during terminal flexion [6]. Several possible etiologies have been suggested, including structural variations of the intercondylar notch and microtrauma leading to the release of a mucin substance [8]. In this case, there was no abnormality in the morphology of the intercondylar notch. Therefore, we considered that excessive stress on the knee associated 


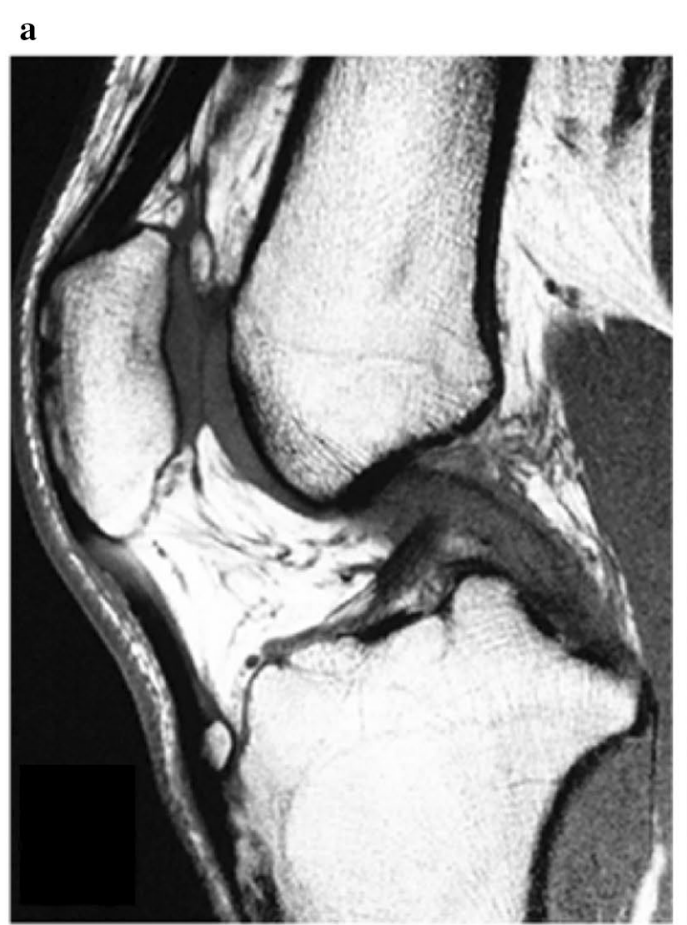

\section{b}

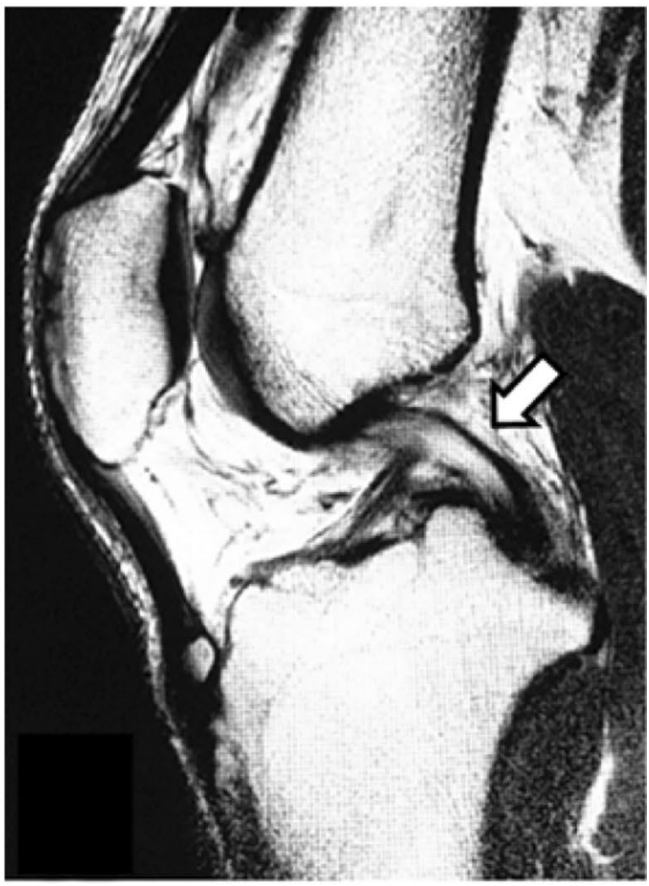

c

d
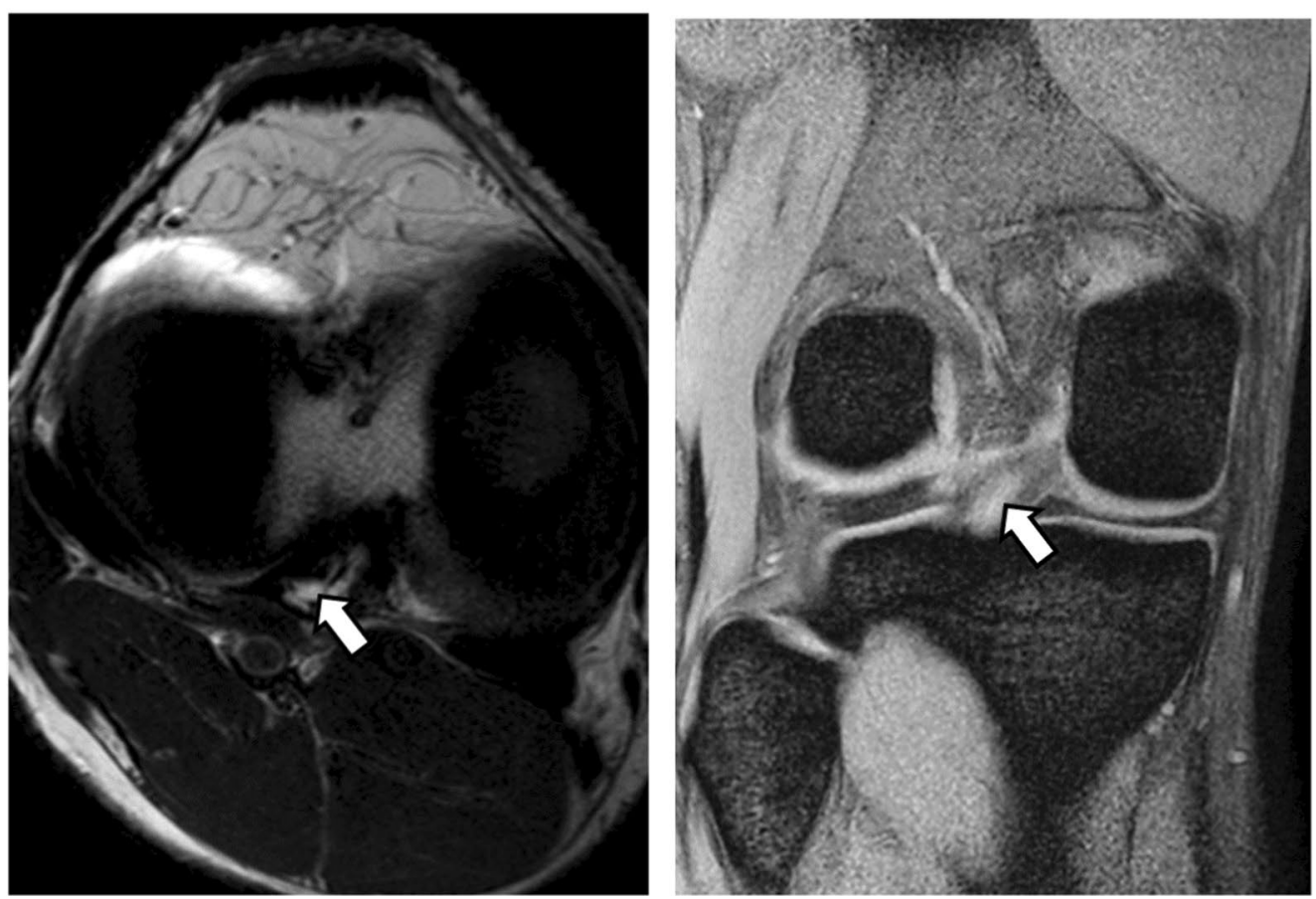

Fig. 1 Preoperative MRI. a Sagittal T1-weighted image of the PCL showing relative increased signal within ligament consistent with diffuse mucoid degeneration. $\mathbf{b}$ Longitudinal increased signal intensity area within the PCL on sagittal T2-weighed images with an adjacent well-defined rim of hypointense PCL fibers (white arrow). c Axial and $\mathbf{d}$ coronal T2-weighed images of the PCL showing high signal intensity area within the PCL (white arrow) 


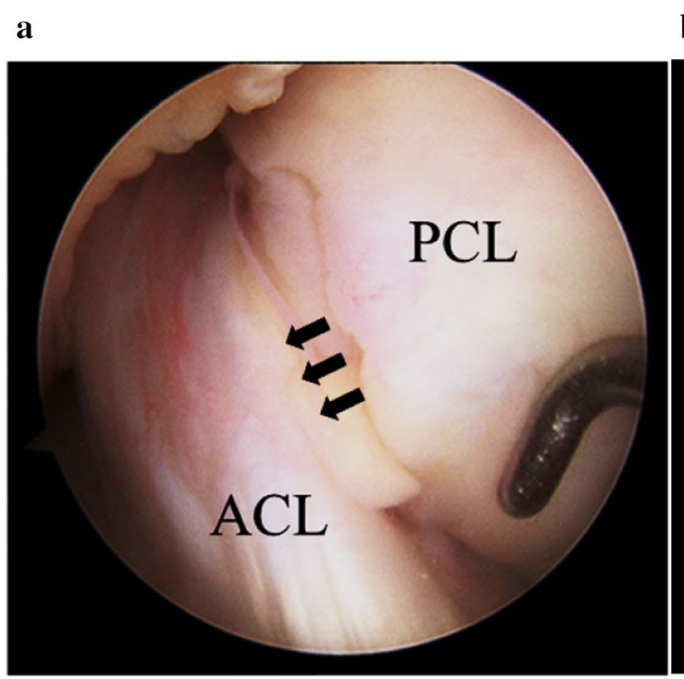

\section{b}

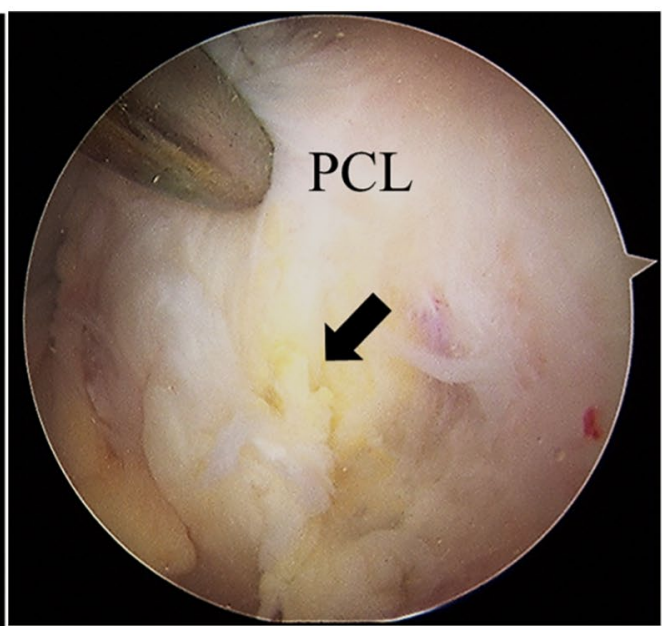

c

d
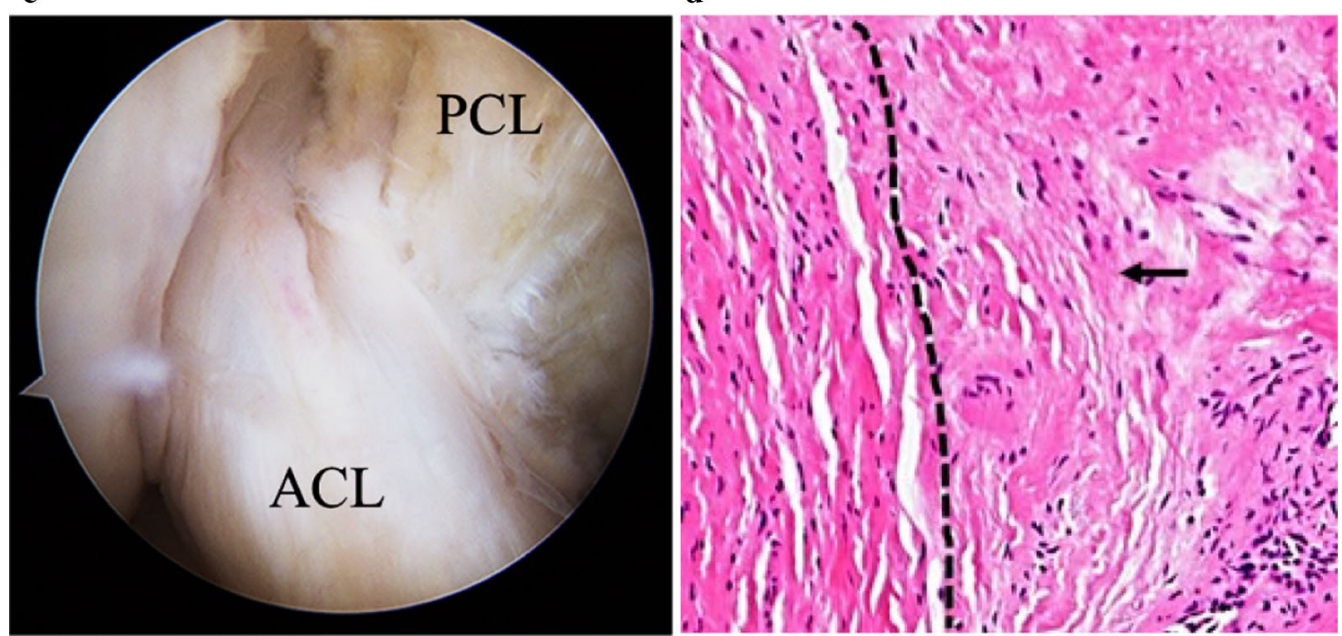

Fig. 2 Arthroscopic findings of the knee and histological examination of PCL. a Arthroscopic examination from anterior view revealed yellowish crumbly tissues along the thickened PCL. Tension and bulk of the PCL were well preserved. Anterior cruciate ligament appearance and tension with probing was normal but was pushed towards lateral wall of the notch (black arrow). b The yellowish tissue was present in deeper region (black arrow) while retention of fluid was not observed within the ligament substance. c The PCL tissue was split, and evidently degenerated tissue was carefully removed while meticulous care was taken to preserve the longitudinal fiber of the PCL. MFC; medial femoral condyle. $\mathbf{d}$ On histologic examination of the PCL, loose fibrocollagenous tissue containing myxedematous changes indicated mucoid degeneration of the ligament (right side of a dotted line, black arrow, Hematoxylin and eosin stain)

with repetitive minor injuries during the sports activity may have caused mucoid degeneration. For treatment of mucoid degeneration of the cruciate ligament, partial excision or debridement is usually performed.
Most authors have reported satisfactory results after these procedures without instability [2-6]. In our case, we excised the PCL in part, and it resulted in complete 
a

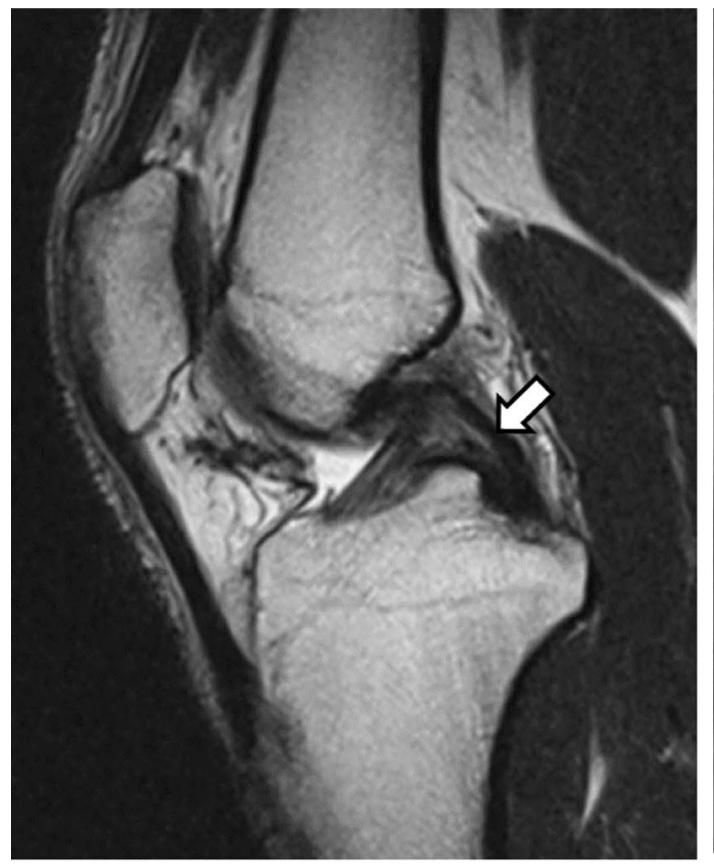

c

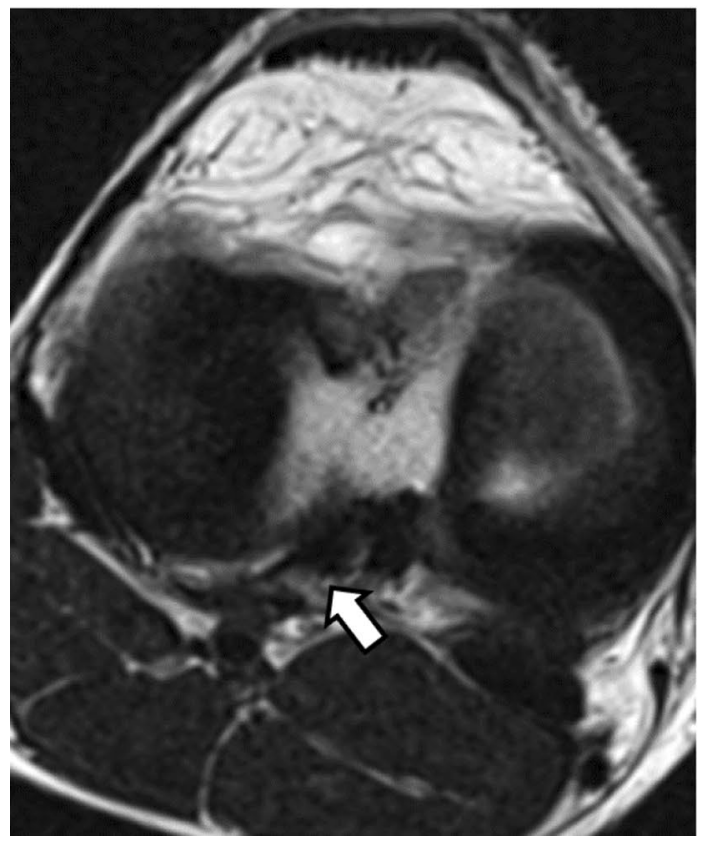

b
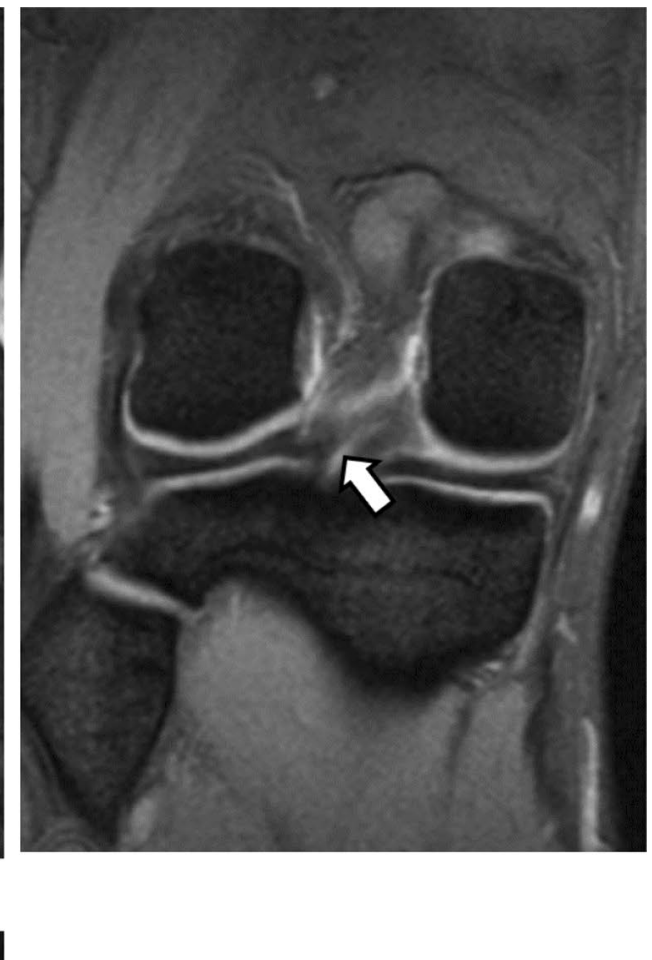


\section{Conclusion}

We conclude that arthroscopic decompression of the PCL may relieve knee pain and facilitate early return to play with good functional results.

\section{Abbreviations}

PCL: Posterior cruciate ligament; ACL: Anterior cruciate ligament; MRI: Magnetic resonance imaging.

\section{Acknowledgements}

The authors would like to acknowledge Rebecca Imaizumi for her assistance in editing the English of this article.

\section{Authors' contributions}

All authors discussed the results and contributed to the final manuscript. RK contributed to reference search, surgery, manuscript preparation, and case report idea; RI contributed to manuscript preparation; HN, TI, SO, TT, and SY contributed to surgery, case report idea, and intellectual content. All authors read and approved the final manuscript.

\section{Funding}

The authors declare that they have received no funding

\section{Availability of data and materials}

The dataset used and analyzed during the current study is available from the corresponding author on reasonable request.

\section{Declarations}

\section{Ethics approval and consent to participate}

The patient was assigned an informed written consent form.

\section{Consent for publication}

Written informed consent was obtained from the patient for publication of this case report and any accompanying images. A copy of the written consent is available for review by the Editor-in-Chief of this journal.

\section{Competing interests}

The authors declare that they have no competing interests.

\section{Acceptable secondary publication}

This article is based on a study first reported in the Seikeigeka 2019 Jan;70(1): 26-29. (in Japanese) [9]. The authors have received approval of secondary publication from the editors of "Seikeigeka" (in Japanese).

\section{Author details}

${ }^{1}$ Department of Orthopaedic Surgery, Hyogo College of Medicine, 1-1 Mukogawa-cho, Nishinomiya, Hyogo 663-8501, Japan. ${ }^{2}$ Department of Orthopaedic Surgery, Nishinomiya Kaisei Hospital, Nishinomiya, Japan.

Received: 17 September 2020 Accepted: 4 May 2021

Published online: 03 June 2021

\section{References}

1. Bergin D, Morrison WB, Carrino JA, Nallamshetty SN, Bartolozzi AR. Anterior cruciate ligament ganglia and mucoid degeneration: coexistence and clinical correlation. AJR Am J Roentgenol. 2004;182(5):1283-7.

2. Ahluwalia W, Sagar DG, Narayan S, Gupta A. Intercondylar ganglion cyst with mucoid degeneration of posterior cruciate ligament of knee: report of a rare case and review of literature. J Orthop Case Rep. 2014;4(1):32-4.

3. Cho SD, Youm YS, Lee CC, Seo DK, Kim TW. Mucoid degeneration of both ACL and PCL. Clin Orthop Surg. 2012;4(2):167-70.

4. Okazaki K, Deguchi S, Katai K, Iwamoto Y. Mucoid degeneration of the posterior cruciate ligament: a case report. Knee Surg Sports Traumatol Arthrosc. 2011;19(1):105-7.

5. Shoji T, Fujimoto E, Sasashige Y. Mucoid degeneration of the posterior cruciate ligament: a case report. Knee Surg Sports Traumatol Arthrosc. 2010;18:130-3.

6. Wang $\mathrm{JH}$, Jangir RR. Mucoid degeneration of posterior cruciate ligament with secondary impingement of anterior cruciate ligament: a rare case report. J Orthop Case Rep. 2015;5(4):44-6.

7. McMonagle JS, Helms CA, Garrett WE, Vinson EN. Tram-track appearance of the posterior cruciate ligament (PCL): correlations with mucoid degeneration, ligamentous stability, and differentiation from $P C L$ tears. AJR Am J Roentgenol. 2013;201(2):394-9.

8. Cha JH, Lee SH, Shin MJ, Choi BK, Bin SI. Relationship between mucoid hypertrophy of the anterior cruciate ligament (ACL) and morphologic change of the intercondylar notch: MRI and arthroscopy correlation. Skeletal Radiol. 2008;37(9):821-6.

9. Iwakura R, Kanto R, Nakayama H, Yoshiya S. Mucoid degeneration of the posterior cruciate ligament in a soccer player. Seikeigeka. 2019;70:26-9 ((in Japanese)).

\section{Publisher's Note}

Springer Nature remains neutral with regard to jurisdictional claims in published maps and institutional affiliations.

Ready to submit your research? Choose BMC and benefit from:

- fast, convenient online submission

- thorough peer review by experienced researchers in your field

- rapid publication on acceptance

- support for research data, including large and complex data types

- gold Open Access which fosters wider collaboration and increased citations

- maximum visibility for your research: over 100M website views per year

At $\mathrm{BMC}$, research is always in progress.

Learn more biomedcentral.com/submissions 